\title{
Pemilihan Kulit Ular Berkualitas Untuk Kerajinan Kulit Menggunakan Metode Analytical Hierarchy Process
}

\author{
Ria Eka Sari \\ Sistem Informasi, STMIK Potensi Utama \\ E-mail: ladiespure@gmail.com
}

\begin{abstract}
Abstrak
Kulit Ular merupakan elemen utama yang sangat menentukan kualitas suatu produk kerajinan. CV. Asia Exotica Medan pada mulanya merupakan industri yang hanya menerima kulit dari pembudidaya ular, dan kemudian sekarang berkembang mengolah kulit ular untuk dijadikan produk dan kerajinan lainnya. Karena kurangnya pengetahuan perusahaan Kulit dibidang industri ini mengakibatkan terjadi kesulitan dalam menentukan keputusan memilih kulit untuk dijadikan bahan kerajinan Tas, Jaket, Sepatu, Dompet dan Aksesoris lainnya yang bagus dan berkualitas, padahal untuk menentukan sebuah kulit layak atau tidaknya sebagai bahan kerajinan diperlukan perhitungan yang sistematis dan akurat agar diperoleh pengambilan keputusan yang tepat. Penggunaan perangkat lunak sistem pendukung keputusan (SPK) dengan metode Analytical Hierarchy Process(AHP) ini terdiri dari 3 kriteria, yaitu kriteria ukuran kulit, fisik kulit dan warna kulit pada suatu kulit ular dan yang menjadi alternatif kulit phyton, sunbean, radiata dan sunbean. Setelah mengetahui parameter, langkah selanjutnya adalah menganalisis kebutuhan sistem, merekayasa pengetahuan, menerapkan metode dan pengujian sistem dengan menggunakan software Super Decisions.
\end{abstract}

Kata Kunci-Sistem Pendukung Keputusan, SPK, AHP, Kulit Ular, Super Decisions

\begin{abstract}
Snake skin is the main element that will determine the quality of a craft product. CV.Asia Exotica was originally a field that only accepts industry of cultivators snake skin, and then now grown to be a snake skin processing and other handicraft products. Because Less of knowledge in the field of industrial enterprises has resulted leather happened difficulty in determining the decision to choose the skin to be used as craft Bag, Jacket, Shoes, Wallets and other accessories are good quality, but to determine whether or not a leather craft materials required as a systematic calculation and accurately in order to obtain the right decision. The use of decision support software system (DSS) with Analytical Hierarchy Process ( AHP) is composed of three criteria, namely is criteria skin, physical skin, skin color in a snake skin and python skin is a viable alternative, sunbean, radiata and sunbean. After knowing the parameters, the next step is to analyze the need of the system, manipulating knowledge, implement the method and system testing using the Super Decisions software.
\end{abstract}

Keywords—Decision Support System, Dss, AHP, Snake Skin, Super Decisions 


\section{PENDAHULUAN}

Kualitas terhadap suatu hasil produksi merupakan hal yang paling diharapkan oleh konsumen. Untuk mencapai hal tersebut tidak lepas dari kebutuhan bahan baku yang berkualitas pula. Apalagi saat ini pemerintah sedang berusaha mengembangkan usaha kecil menengah untuk dapat lebih produktif. Salah satu sektor penunjang ekonomi domestik yaitu kerajinan kulit. Kulit hewan, terutama ular merupakan bahan baku yang baik dan unik untuk pembuatan berbagai jenis kerajinan dari kulit mulai dari sepatu, sandal, jaket, tas, topi, ikat pinggang, gantungan kunci, sovenir dan berbagai asesoris di dalam ruangan yang sangat indah dan menarik. Permilihan bahan baku yang baik akan menentukan kualitas dari sebuah hasil produksi, begitu juga dengan penentuan kualitas bahan baku kulit yaitu kulit ular sangat tergantung dari proses pengolahannya yang selama ini menggunakan cara manual untuk menentukan kualitasnya, tentunya hanya orang tertentu saja yang dapat menentukan kualitas kulit tersebut tanpa ada dukungan data yang objektif, dan tidak dapat ditentukan oleh orang lain, jadi dari masalah yang terjadi penulis perlu melakukan penelitian untuk mencoba menyelesaikan masalah yang terjadi. Dalam hal penulis akan menganalisis, merancang dan menguji metode Analitycal Hierarchy Process (AHP) untuk pengolahan datanya yang nantinya informasi yang dihasilkan berguna untuk pengrajin kerajinan kulit ular dalam menentukan kualitas kulit yang digunakan dalam proses produksi.

\subsection{Sistem Pendukung Keputusan}

Konsep Sistem Pendukung Keputusan pertama kali diperkenalkan pada awal tahun 1970-an oleh Michael S. Scott Morton dengan istilah Management Decision System (Sprague, 1982). Konsep pendukung keputusan ditandai dengan sistem interaktif berbasis komputer yang membantu pengambil keputusan memanfaatkan data dan model untuk menyelesaikan masalahmasalah yang tidak terstruktur. Pada dasarnya SPK diracang untuk mendukung seluruh tahap pengambilan keputusan mulai dari mengidentifikasi masalah, memilih data yang relevan, menentukan pendekatan yang digunakan dalam prosen pengambilan keputusan, sampai mengevaluasi pemilihan alternatif[1].

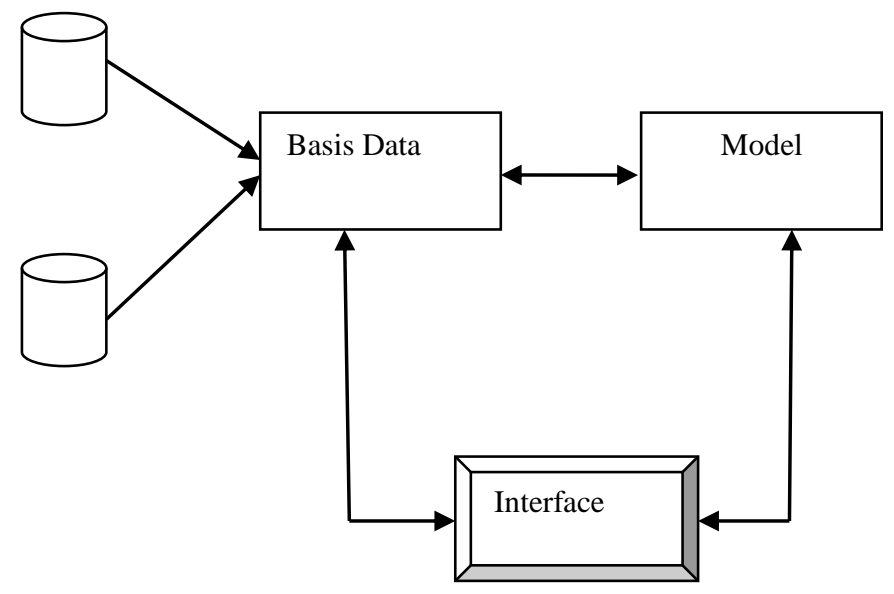

Gambar 1. Komponen Sistem Pendukung Keputusan

Gambar 1 memperlihatkan Sistem Pendukung Keputusan terdiri atas tiga komponen penting utama untuk menentukan kapabilitas teknis, yaitu:

1. Subsistem manajemen data, subsistem manajemen data memasukkan satu database yang berisi data yang relevan untuk situasi dan dikelola oleh perangkat lunak yang disebut sistem manajemen database (DBMS). 
2. Subsistem manajemen model, merupakan paket perangkat lunak yang memasukkan model keuangan, statistik, ilmu manajemen atau model kuantitatif lainnya yang memberikan kapabilitas analitik dan manajemen perangkat lunak yang tepat.

3. Antarmuka Pengguna, pengguna berkomunikasi dengan memerintahkan DSS melalui subsistem ini[2].

\subsection{Analytic Hierarchy Process (AHP)}

Analytical Hierarchy Process (AHP) dikembangkan oleh Thomas L. Saaty pada tahun 1970-an. Metode ini merupakan salah satu model pengambilan keputusan multikriteria yang dapat membantu kerangka berpikir manusia dimana faktor logika, pengalaman pengetahuan, emosi dan rasa dioptimasikan ke dalam suatu proses sistematis. Pada dasarnya, AHP merupakan metode yang digunakan untuk memecahkan masalah yang kompleks dan tidak terstruktur ke dalam kelompok-kelompoknya, dengan mengatur kelompok tersebut ke dalam suatu hierarki, kemudian memasukkan nilai numerik sebagai pengganti persepsi manusia dalam melakukan perbandingan relatif. Dengan suatu hipotesa maka akan dapat ditentukan elemen mana yang mempunyai prioritas tertinggi[1].

\subsubsection{Tahapan Analytic Hierarchy Process(AHP)}

Secara umum, tahapan-tahapan proses yang harus dilakukan dalam menggunakan AHP untuk memecahkan suatu masalah adalah sebagai berikut:

1. Mendefenisikan permasalahan dan menentukan tujuan. Bila AHP digunakan untuk memilih alternatif atau menyusun prioritas alternatif, maka tahap ini dilakukan pengembangan alternatif.

2. Menyusun masalah ke dalam suatu struktur hierarki sehingga permasalahan yang kompleks dapat ditinjau dari sisi yang detail dan terukur.

3. Menyusun prioritas untuk tiap elemen masalah pada setiap hierarki. Prioritas ini dihasilkan dari suatu matriks perbandingan berpasangan antara seluruh elemen pada tingkat hierarki yang sama.

4. Melakukan pengujian konsistensi terhadap perbandingan antar elemen yang didapatkan pada tiap tingkat hierarki. Thomas L. Saaty membuktikan bahwa Indeks Konsistensi dari matriks berordo $-\mathrm{n})[3]$.

\subsubsection{Landasan Aksiomatik (AHP)}

Analytic Hierarchy Process (AHP) mempunyai landasan aksiomatik yang terdiri dari:

1. Reciprocal Comparison, yang mengandung arti si pengambil keputusan harus bisa membuat perbandingan dan menyatakan preferensinya. Preferensinya itu sendiri harus memenuhi syarat resiprokal yaitu kalau A lebih disukai dari B dengan skala $\mathrm{x}$, maka B lebih disukai dari A dengan skala.

2. Homogenity, yang mengandung arti preferensi seseorang harus dapat dinyatakan dalam skala terbatas atau dengan kata lain elemen-elemennya dapat dibandingkan satu sama lain. Kalau aksioma ini tidak dapat dipenuhi maka elemen-elemen yang dibandingkan tersebut tidak homogenous dan harus dibentuk suatu 'cluster' (kelompok elemen-elemen) yang baru.

3. Independence, yang berarti preferensi dinyatakan dengan mengasumsikan bahwa kriteria tidak dipengaruhi oleh alternatif-alternatif yang ada melainkan oleh objektif secara keseluruhan. Ini menunjukkan bahwa pola ketergantungan atau pengaruh dalam model AHP adalah searah keatas, Artinya perbandingan antara elemen-elemen dalam satu level dipengaruhi atau tergantung oleh elemen-elemen dalam level di atasnya.

4. Expectations, artinya untuk tujuan pengambilan keputusan, struktur hirarki diasumsikan lengkap. Apabila asumsi ini tidak dipenuhi maka si pengambil keputusan tidak memakai seluruh kriteria dan atau objektif yang tersedia atau diperlukan sehingga keputusan yang diambil dianggap tidak lengkap[1]. 


\subsection{Kulit Ular}

Reptil sejak lama telah dimanfaatkan oleh masyarakat. Sebagai contoh ular merupakan sumberdaya fauna yang banyak dimanfaatkan sebagai salah satu komoditi yang mempunyai nilai ekonomi tinggi. Ular dimanfaatkan antara lain sebagai bahan percobaan medis, satwa peliharaan, bahan kerajinan (tas, sepatu, tali pinggang, dan lain-lain) dan dikonsumsi (Situngkir, 2009)[4]. Kulit hewan, terutama ular merupakan bahan baku yang baik dan unik untuk pembuatan berbagai jenis kerajinan dari kulit mulai dari sepatu, sandal, jaket, tas, topi, ikat pinggang, gantungan kunci, sovenir dan berbagai asesoris yang sangat indah dan menarik. Kulit ular yang berkualitas sangat mempengaruhi nilai jual dari kerajinan yang nantinya akan dipasarkan. Karena tidak semua jenis kulit ular itu bagus untuk diolah, harus diamati oleh orang yang berpengalaman dibidangnya agar dapat menentukan kulit mana yang layak untuk diolah ke proses selanjutnya.

Pemilihan bahan baku yang baik akan menentukan kualitas dari sebuah hasil produksi, begitu juga dengan penentuan kualitas bahan baku kulit yaitu kulit ular sangat tergantung dari proses pengolahananya, yang selama ini menggunakan cara manual untuk menentukan kualitasnya, tentunya hanya orang tertentu saja yang dapat menentukan kualitas kulit tersebut tanpa ada dukungan data yang objektif, dan tidak dapat ditentukan oleh orang lain. Sistem penunjang keputusan dengan metode AHP ini diharapkan mampu mengatasi persoalan penentuan kualitas yang manual tersebut menjadi lebih mudah, dikarenakan orang lain dapat menentukan kualitas secara objektif berdasarkan data yang dimiliki dari bahan baku tersebut.

\subsection{Super Decisions sebagai Tools}

Sebuah perangkat lunak yang mendukung collaborative decision dan sistem perangkat keras yang memfasilitasi grup membuat keputusan yang lebih efisien, analitis, dan yang dapat dibenarkan. Memungkinkan interaksi real-time dari tim manajemen untuk mencapai consensus decision. Metode yang digunakan pada program Super Decision adalah Analytical Hierarchy Process (AHP). Struktur untuk seluruh proses pengambilan keputusan. Sebuah tool yang memfasilitasi kerjasama anatar beberapa pihak yang berkepentingan.

\section{METODE PENELITIAN}

Penelitian ini dilakukan dalam beberapa tahap, yaitu Tahap Persiapan, meliputi melakukan kajian materi tentang metode Analytical Hierarchy Process yang telah dikumpulkan dari beberapa sumber. Yang berguna untuk membuat suatu masalah lebih terstruktur. Tahap kedua yaitu mengimplentasikan masalah tersebut kedalam metode Analytical Hierarchy Process sampai mendapatkan sebuah keputusan yang nantinya berguna untuk memilih kulit mana yang paling berkualitas. Tahap terkhir yaitu melakukan pengujian dengan tools Super Decisions untuk menguji tingkat konsistensi dan prioritas apakah sudah sesuai dengan aturan yang ada.

\section{HASIL DAN PEMBAHASAN}

\subsection{Super Decisions sebagai Tools}

AnalyticalHierarcy Process (AHP) adalah suatu metode analisis dan sintesis yang dapat membantu proses pengambilan keputusan. AHP merupakan alat pengambil keputusan yang powerfull dan akurat karena adanya skala atau bobot yang telah ditentukan dan menggunakan hirarki yang terdiri dari tiga level yaitu tujuan atau goal, kriteria dan alternatif. Hierarki yang digunakan adalah pada gambar 2. 
Citec Journal, Vol. 1, No. 4, Agustus 2014 - Oktober 2014

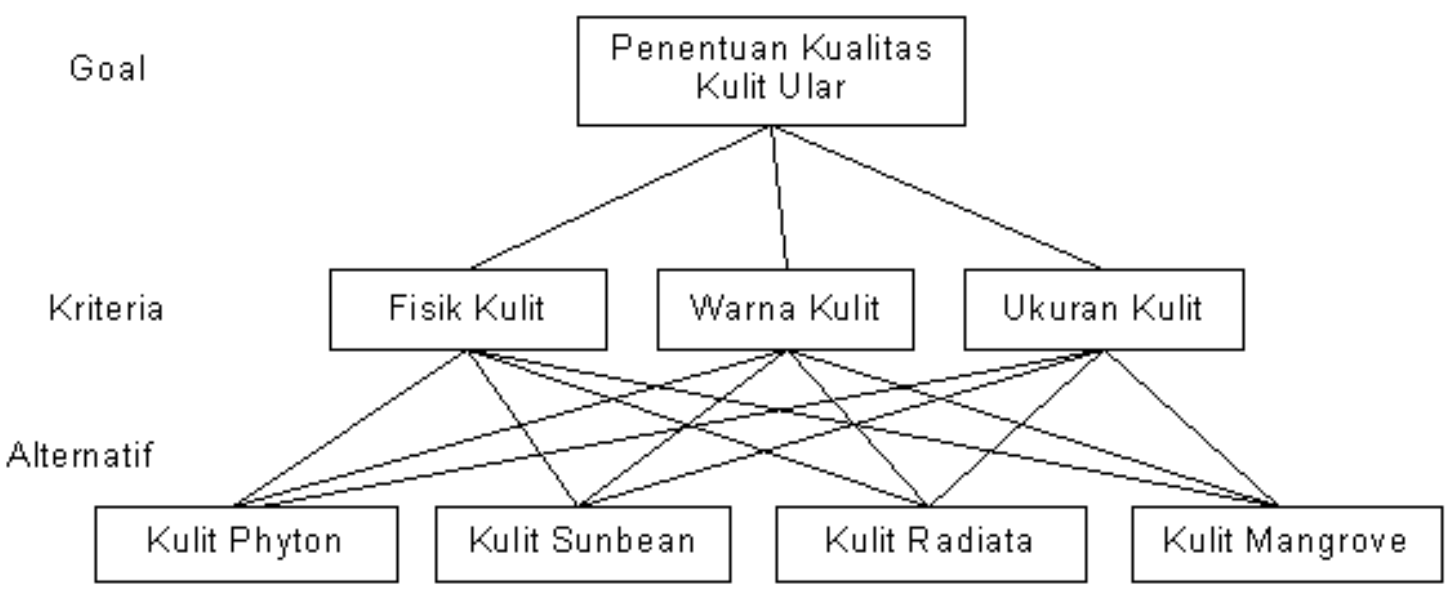

Gambar 2. Hirarki AHP Penentuan Kualitas Kulit Ular

Gambar 2 merupakan susunan hirarki AHP Penentuan Kualitas Kulit Ular, berikut akan dijelaskan tujuan, kriteria dan alternatif yang digunakan:

1. Goal, menjelaskan keseluruhan keputusan yaitu tujuan yang hendak dicapai baik secara keseluruhan maupun perkriteria. Goal dalam penelitian ini adalah menentukan kualitas kulit ular yang berkualitas untuk dijadikan kerajinan.

2. Kriteria yang digunakan adalah Kondisi Fisik Kulit, Warna Kulit, Ukuran Kulit.

3. Alternatif yang digunakan adalah Kulit Phyton, Kulit Sunbean, Kulit Radiata dan Kulit Mangrove.

\subsubsection{Membuat Matriks Perbandingan Berpasangan Kriteria}

Tahapan ini pemberian bobot masing-masing kriteria menggunakan model AHP (Analytical Hieracrchy Process). Data kriteria didapatkan dari kuesioner dan wawancara langsung dengan staff pada bagian gudang yang langsung membandingkan kriteria dan kriteria sesuai dengan tabel kepentingan dan sampel hasil matriks perbandingan berpasangan dapat dilihat pada tabel 1 .

Tabel 1. Matriks Perbandingan Berpasangan Kriteria

\begin{tabular}{|l|c|c|c|}
\hline \multicolumn{1}{|c|}{ Kriteria } & Ukuran Kulit & Fisik Kulit & Warna Kulit \\
\hline Ukuran Kulit & $1 / 1$ & $5 / 1$ & $3 / 1$ \\
\hline Fisik Kulit & $1 / 5$ & $1 / 1$ & $1 / 2$ \\
\hline Warna Kulit & $1 / 3$ & $2 / 1$ & $1 / 1$ \\
\hline
\end{tabular}

Tabel 1 memperlihatkan matriks Perbandingan Berpasangan yang terdiri atas:

1. Nilai perbandingan untuk dirinya sendiri (Ukuran Kulit, Warna Kulit dan Fisik Kulit) bernilai 1 berarti intensitas kepentingannya sama.

2. Perbandingan Ukuran Kulit dengan Warna Kulit bernilai 3 berarti Ukuran Kulit lebih penting daripada nilai Warna Kulit.

3. Perbandingan Ukuran Kulit dengan Fisik Kulit bernilai 5 berarti Ukuran Kulit lebih penting daripada nilai Fisik Kulit.

4. Perbandingan yang selanjutnya mempunyai nilai yang sama dapat disesuaikan penjelasannya dengan yang sebelumnya.

5. Sedangkan perbandingan kebaris bawah adalah kebalikan dari nilai yang telah dimasukkan. 


\subsubsection{Membuat Matriks Perbandingan Berpasangan Alternatif}

Pada tahap ini alternatif dibandingkan sesuai dengan kriteria ukuran kulit yang datanya didapatkan dari hasil wawancara dan kuesioner kemudian diolah kedala matriks perbandingan berpasangan sesuai kriteria. Hasil perhitungan dapat dilihat pada tabel 4.2.

Tabel 2. Hasil Perbandingan Berpasangan Kriteria Ukuran Kulit

\begin{tabular}{|l|l|l|l|l|}
\hline Ukuran Kulit & Phyton & Sunbean & Radiata & Mangrove \\
\hline Phyton & $1 / 1$ & $3 / 1$ & $2 / 1$ & $1 / 1$ \\
\hline Sunbean & $1 / 3$ & $1 / 1$ & $1 / 5$ & $1 / 2$ \\
\hline Radiata & $1 / 2$ & $5 / 1$ & $1 / 1$ & $2 / 1$ \\
\hline Mangrove & $1 / 1$ & $2 / 1$ & $1 / 2$ & $1 / 1$ \\
\hline
\end{tabular}

Tabel 2 memperlihatkan matriks Perbandingan Berpasangan yang terdiri atas:

1. Nilai perbandingan untuk dirinya sendiri (Phyton dan Phyton, Sunbean dan Sunbean, dan Radiata dan Radiata, Mangrove dan Mangrove) bernilai 1 berarti intensitas kepentingannya sama.

2. Perbandingan Phyton dengan Sunbean bernilai 3 berarti Phyton lebih penting daripada nilai Sunbean

3. Perbandingan Phyton dengan Radiata bernilai 2 dapat dijelaskan bahwa nilai perbandingan Phyton berdekatan.

4. Perbandingan Phyton dengan Mangrove bernilai 1 berarti intensitas kepentingannya sama.

5. Perbandingan Sunbean dengan Phyton bernilai 3 berarti intensitas kepentinganya sama.

6. Perbandingan Sunbean dengan Radiata bernilai 5 berarti intensitas kepentinganya lebih penting.

7. Perbandingan Sunbean dengan Mangrove bernilai 2 berarti intensitas kepentinganya sama.

8. Perbandingan yang selanjutnya mempunyai nilai yang sama dapat disesuaikan penjelasannya dengan yang sebelumnya.

9. Sedangkan perbandingan kebaris bawah adalah kebalikan dari nilai yang telah dimasukkan.

Tabel 3. Hasil Perbandingan Berpasangan Kriteria Fisik Kulit

\begin{tabular}{|l|c|c|c|c|}
\hline Fisik Kulit & Phyton & Sunbean & Radiata & Mangrove \\
\hline Phyton & $1 / 1$ & $1 / 2$ & $1 / 3$ & $1 / 1$ \\
\hline Sunbean & $2 / 1$ & $1 / 1$ & $1 / 3$ & $1 / 2$ \\
\hline Radiata & $3 / 1$ & $3 / 1$ & $1 / 1$ & $2 / 1$ \\
\hline Mangrove & $1 / 1$ & $2 / 1$ & $1 / 2$ & $1 / 1$ \\
\hline
\end{tabular}

Tabel 4. Hasil Perbandingan Berpasangan Kriteria Warna Kulit

\begin{tabular}{|l|c|c|c|c|}
\hline $\begin{array}{l}\text { Warna } \\
\text { Kulit }\end{array}$ & Phyton & Sunbean & Radiata & Mangrove \\
\hline Phyton & $1 / 1$ & $1 / 3$ & $1 / 2$ & $1 / 4$ \\
\hline Sunbean & $3 / 1$ & $1 / 1$ & $1 / 2$ & $1 / 2$ \\
\hline Radiata & $2 / 1$ & $2 / 1$ & $1 / 1$ & $1 / 4$ \\
\hline Mangrove & $4 / 1$ & $2 / 1$ & $4 / 1$ & $1 / 1$ \\
\hline
\end{tabular}


Citec Journal, Vol. 1, No. 4, Agustus 2014 - Oktober 2014

ISSN: 2354-5771

\subsubsection{Hasil Analisa Metode AHP}

Hasil analisa bobot dari kriteria dan alternative yang sudah dihitung dapat dilihat pada gambar dibawah ini:

\begin{tabular}{|l|c|c|c|c|c|}
\hline Kriteria & Ukuran Kulit & Fisik Kulit & Warna Kulit & Nilai Eigen & Bobo: \\
\hline Ukuran Kulit & 1.0000 & 5.0000 & 3.0000 & 0.6401 & $64 \%$ \\
\hline Fisik Kulit & 0.2000 & 1.0000 & 0.5000 & 0.1242 & $12 \%$ \\
\hline Warna Kulit & 0.3333 & 2.000 & 1.0000 & 0.2296 & $23 \%$ \\
\hline Jumlah & $\mathbf{1 . 5 3 3 3}$ & $\mathbf{8 . 0 0 0 0}$ & $\mathbf{4 . 5 0 0 0}$ & $\mathbf{1 . 0 0 0 0}$ & $\mathbf{1 0 0 \%}$ \\
\hline
\end{tabular}

Gambar 3. Hasil Analisa Kriteria

\begin{tabular}{|c|c|c|c|c|c|c|}
\hline Ukuran Kulit & Phyton & Sunbean & Radiata & Mangrove & $\begin{array}{c}\text { Nilai } \\
\text { Eigen }\end{array}$ & Bobot \\
\hline Shyton & 1.0000 & 3.0000 & 2.0000 & 1.0000 & 0.3579 & $35 \%$ \\
\hline Sunbean & 0.3333 & 1.0000 & 0.2000 & 0.5000 & 0.0913 & $9 \%$ \\
\hline Radiata & 0.5000 & 5.0000 & 1.0000 & 3.0000 & 0.3320 & $33 \%$ \\
\hline Mangrove & 1.0000 & 2.0000 & 0.3333 & 1.0000 & 0.2186 & $21 \%$ \\
\hline Jumlah & $\mathbf{2 . 8 3 3 3}$ & $\mathbf{1 1 . 0 0 0 0}$ & $\mathbf{3 . 7 0 0 0}$ & $\mathbf{4 . 5 0 0 0}$ & $\mathbf{1 . 0 0 0 0}$ & $\mathbf{1 0 0 \%}$ \\
\hline
\end{tabular}

Gambar 4. Hasil Analisa Alternatif berdasarkan kriteria Ukuran Kulit

\begin{tabular}{|c|c|c|c|c|c|c|}
\hline Fisik Kulit & Phyton & Sunbean & Radiata & Mangrove & $\begin{array}{l}\text { Nilai } \\
\text { Eigen }\end{array}$ & Bobot \% \\
\hline $\mathrm{Ph}$ ton & 1.0000 & 0.5000 & 0.3333 & 1.0000 & 0.1469 & $14 \%$ \\
\hline Suibean & 2.0000 & 1.0000 & 0.3333 & 0.5000 & 0.1758 & $17 \%$ \\
\hline Raliata & 3.0000 & 3.0000 & 1.0000 & 2.0000 & 0.4492 & $44 \%$ \\
\hline Mangrove & 1.0000 & 2.0000 & 0.5000 & 1.0000 & 0.2281 & $22 \%$ \\
\hline Jumlah & 7.0000 & 6.5000 & 2.1666 & 4.5000 & 1.0000 & $100 \%$ \\
\hline
\end{tabular}

Gambar 5. Hasil Analisa Alternatif berdasarkan kriteria Fisik Kulit 


\begin{tabular}{|c|c|c|c|c|c|c|}
\hline Warna Kulit & Phyton & Sunbean & Radiata & Mangrove & $\begin{array}{l}\text { Nilai } \\
\text { Eigen }\end{array}$ & Bobot \\
\hline Pigton & 1.0000 & 0.3333 & 0.5000 & 0.2500 & 0.0916 & $9 \%$ \\
\hline Sunbean & 3.0000 & 1.0000 & 0.5000 & 0.5000 & 0.1948 & $19 \%$ \\
\hline Radiata & 2.0000 & 2.0000 & 1.0000 & 0.2500 & 0.2151 & $21 \%$ \\
\hline Mangrove & 4.0000 & 2.0000 & 4.0000 & 1.0000 & 0.4985 & $49 \%$ \\
\hline Jumlah & 10.0000 & 5.3333 & 6.0000 & 2.0000 & 1.0000 & $100 \%$ \\
\hline
\end{tabular}

Gambar 6. Hasil Analisa Alternatif berdasarkan kriteria Warna Kulit

Setelah mendapatkan kriteria penentuan kualitas kulit terpenting dari masing-masing kriteria, langkah selanjutnya adalah mengalikan nilai tersebut dengan nilai akhir dari bobot kriteria.Dari hasil akhir perkalian matrik tersebut, maka dapat dilihat kriteria untuk Phyton dengan nilai 0.2700 atau 27\%, Sunbean dengan nilai 0.1262 atau $12 \%$, Radiata dengan nilai 0.3190 atau $31 \%$, serta Mangrove dengan nilai 0.2857 atau 28\%. Hasil analisa menyatakan alternatif yang terpilih menjadi kulit yang berkualitas untuk dijadikan bahan baku kerajinan adalah:

\begin{tabular}{|l|c|c|c|c|c|}
\hline Bobot & $\begin{array}{c}\text { Ukuran } \\
\text { Kulit }\end{array}$ & Fisik Kulit & Warna Kulit & $\begin{array}{c}\text { Bobot } \\
\text { Final }\end{array}$ & Rank \\
\hline Phyton & 0.3579 & 0.1469 & 0.0916 & 0.2700 & 3 \\
\hline Sunbean & 0.0913 & 0.1758 & 0.1948 & 0.1262 & 4 \\
\hline Radiata & 0.3320 & 0.4492 & 0.2151 & 0.3190 & 1 \\
\hline Mangrove & 0.2186 & 0.2281 & 0.4985 & 0.2857 & 2 \\
\hline
\end{tabular}

Gambar 7. Hasil Analisa Ranking Perhitungan Manual

Didapatkan kesimpulan bahwa kulit Radiata mendapat peringkat pertama Sebagai hasil keputusan yang paling diusulkan sebagai bahan baku kulit untuk kerajinan nantinya. Kulit Mangrove peringkat kedua, Kulit Phyton peringkat ketiga dan Kulit Sunbean peringkat keempat.

1. Radiata (Peringkat Pertama)

2. Mangrove (Peringkat Kedua)

3. Phyton (Peringkat Ketiga)

4. Sunbean (Peringkat Keempat) 
Citec Journal, Vol. 1, No. 4, Agustus 2014 - Oktober 2014

\subsection{Pengujian Tool Super Decisions}

Tahap ini melakukan pengujian pada tool super decision berikut Setelah semua Cluster dihubungkan dengan semua Node, maka akan terlihat seperti apada gambar 8 .

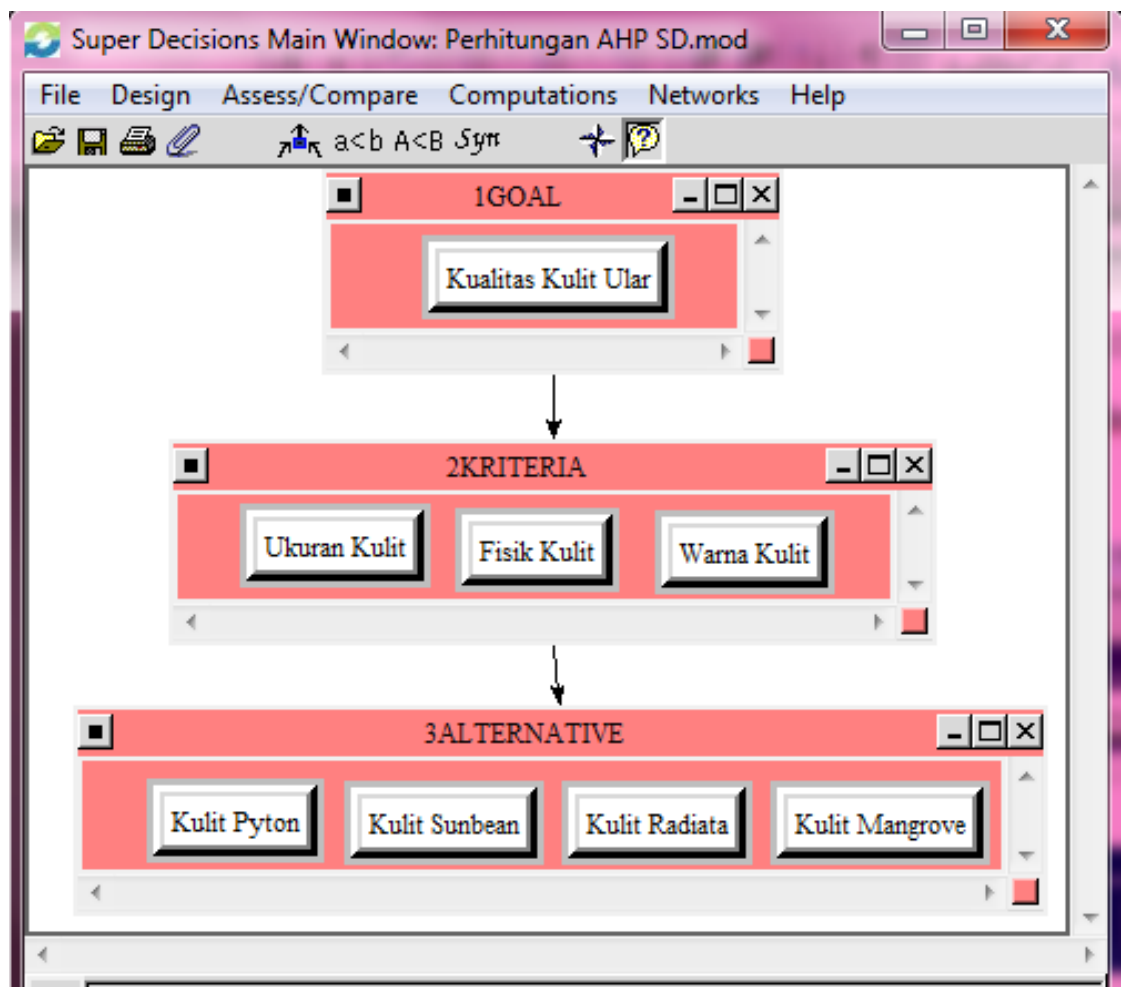

Gambar 8. Cluster Yang Telah Terhubung

Setelah semua Cluster terhubung, langkah selanjutnya adalah melakukan perbandingan antar Cluster dengan mengisi data pada jendela Questionnaire dengan mengklik menu Assess/Compare lalu klik Do Comparison untuk pengisian data seperti pada gambar 9.

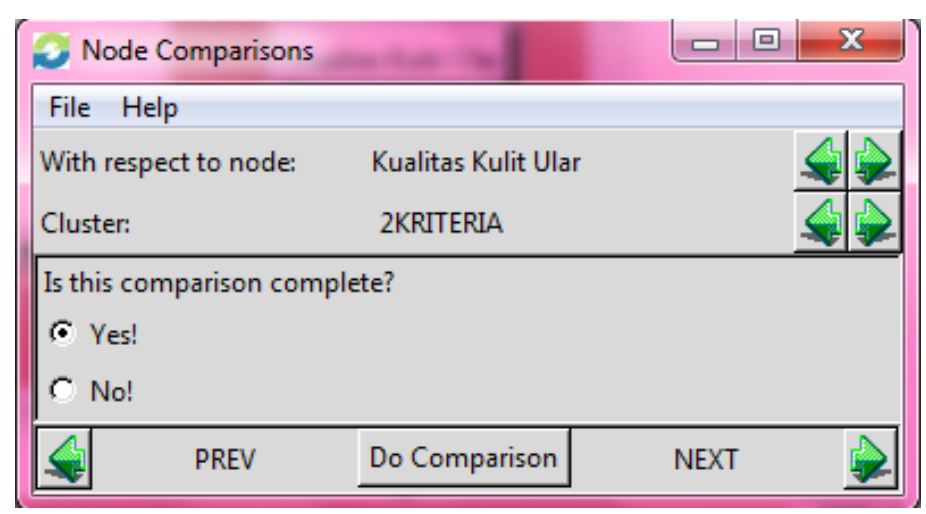

Gambar 9. Perbandingan Antara Cluster

Pada langkah awal menentukan bobot kriteria, inputkan nilai matriks berpasangan ke software super decision seperti pada gambar 10. 


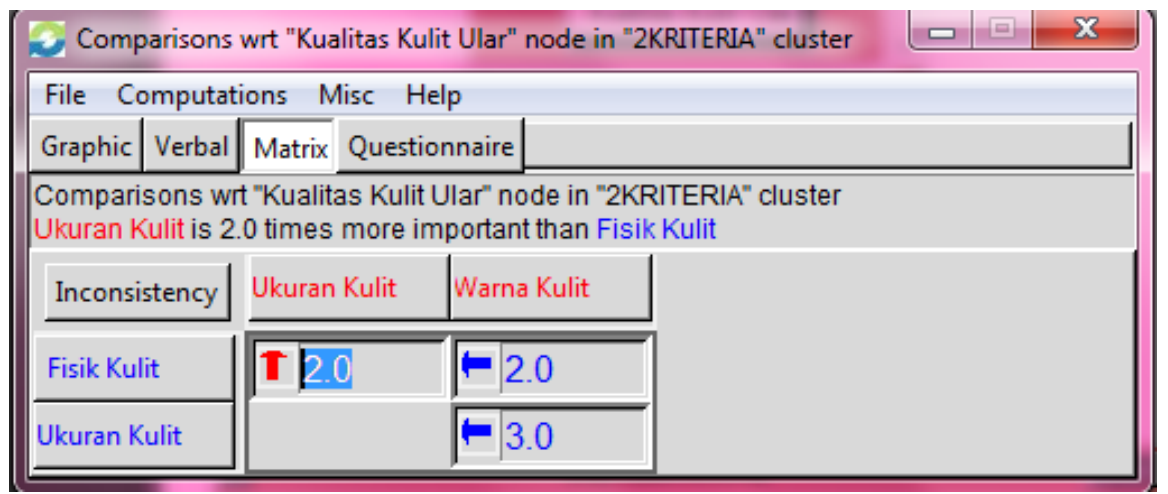

Gambar 10. Input Nilai Matriks Berpasangan Perbandingan Kriteria

Gambar 10 memperlihatkan, nilai matriks berpasangan yang didapatkan akan dimasukkan ke dalam software super decisions untuk dilakukan proses menentukan bobot kriteria berdasarkan goal maka perbandingan kriteria dapat dijelaskan pada gambar 11.

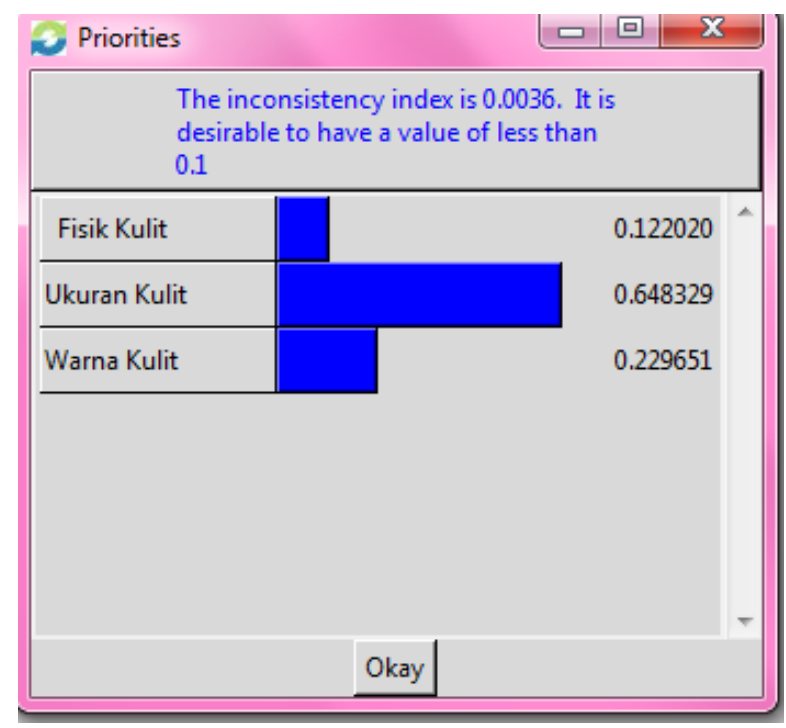

Gambar 11. Hasil Pembobotan Nilai Matriks Berpasangan Kriteria

Dari hasil proses pembobotan nilai matriks berpasangan, maka didapatkan hasil perbandingan bobot prioritas yaitu:

1. Ukuran Kulit menjadi prioritas utama dalam memilih kriteria untuk perbaikan jalan dengan bobot kriteria sebesar 0,6483 .

2. Fisik Kulit menjadi prioritas kedua yaitu dengan bobot prioritas sebesar 0.1220.

3. Warna Kulit sebagai prioritas ketiga dengan bobot prioritas sebesar 0.2296. 
Citec Journal, Vol. 1, No. 4, Agustus 2014 - Oktober 2014

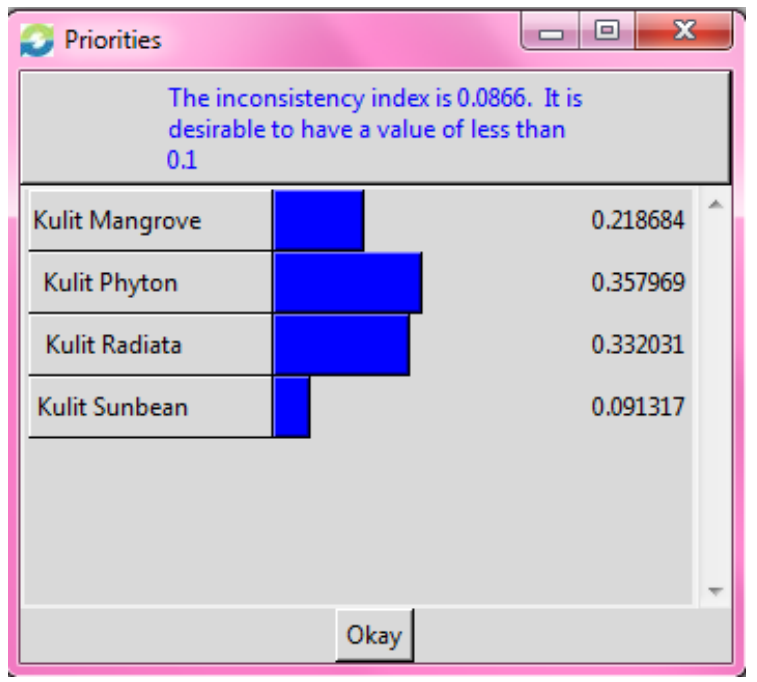

Gambar 12.Hasil Bobot Prioritas Perbandingan Alternatif Berdasarkan Ukuran Kulit

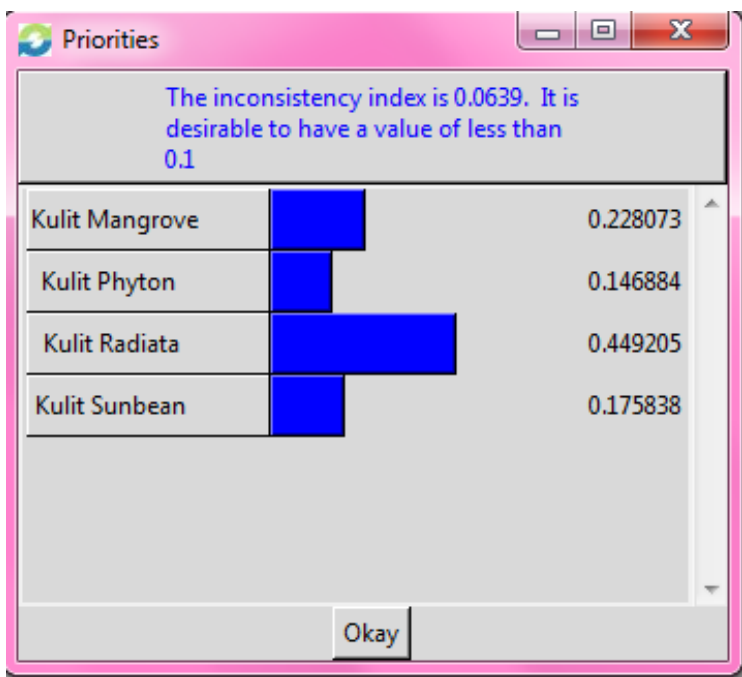

Gambar 13. Hasil Bobot Prioritas Perbandingan Alternatif Berdasarkan Kriteria Fisik Kulit

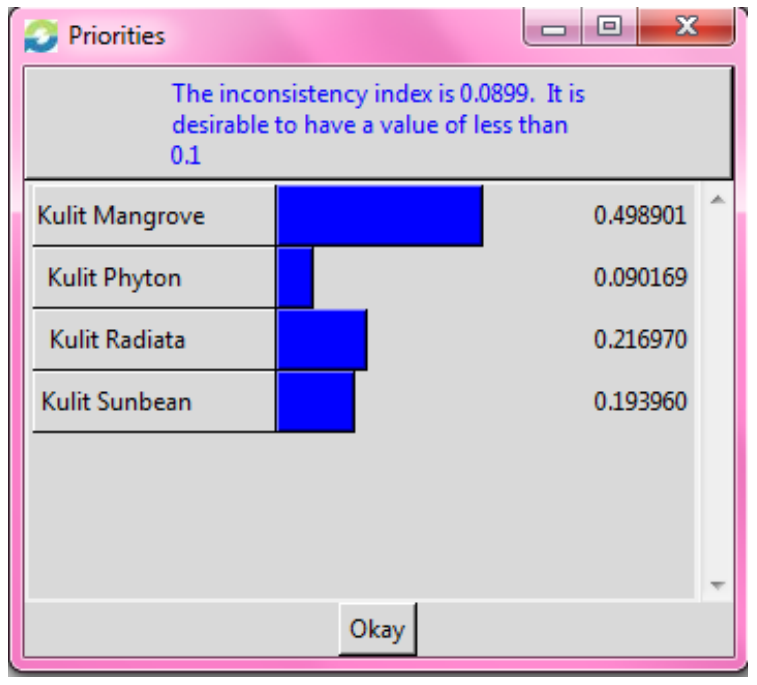

Gambar 14. Hasil Bobot Prioritas Perbandingan Alternatif Berdasarkan Kriteria Warna Kulit 


\section{Alternative Rankings}

\begin{tabular}{|c|c|c|c|c|c|c|}
\hline Graphic & Alternatives & Total & Normal & Ideal & Ranking \\
\hline \hline & Kulit Mangrove & 0.1421 & 0.2842 & 0.8883 & 2 \\
\hline \hline & Kulit Phyton & 0.1354 & 0.2707 & 0.8462 & 3 \\
\hline \hline & Kulit Radiata & 0.1600 & 0.3199 & 1.0000 & 1 \\
\hline \hline & & Kulit Sunbean & 0.0626 & 0.1252 & 0.3914 & 4 \\
\hline \hline
\end{tabular}

Gambar 15. Laporan Lengkap Hasil Analisa

\section{KESIMPULAN}

Hasil perhitungan data sampel untuk menentukan ranking Kualitas Kulit Ular yang paling didukung untuk kerajinan dapat dilihat pada tabel 4.

Tabel 4. Bobot Final dan Ranking Alternatif

\begin{tabular}{c|c|c|c|c|}
\hline No & Alternatif & $\begin{array}{c}\text { Pengujian } \\
\text { Software }\end{array}$ & Pengujian Manual & Ranking \\
\hline 1 & Kulit Radiata & 0.3199 & 0.3190 & 1 \\
\hline 2 & Kulit Mangrove & 0.2842 & 0.2857 & 2 \\
\hline 3 & Kulit Phyton & 0.2707 & 0.2700 & 3 \\
\hline 4 & Kulit Sunbean & 0.1252 & 0.1262 & 4 \\
\hline
\end{tabular}

1. Tabel 4 merupakan perbandingan hasil perhitungan dengan cara manual, dan dengan perhitungan Super Decisions, dari hasil yang dibandingkan terdapat nilai pada beberapa kriteria. Perbedaan yang terjadi pada empat digit angka dibelakang koma, sehingga hasil akhir antara perhitungan analisis manual dengan perhitungan analisis Super Decisions dapat dikatakan konsisten.

2. Dari hasil perbandingan, didapatkan hasil akurasi manual dan dengan software terendah $80 \%$ dan akurasi tertinggi $95 \%$.

3. Kriteria yang berpengaruh terhadap penentuan kualitas kulit ular di CV. Asia Exotica Medan adalah kriteria ukuran kulit dengan nilai 0.6401 (64\%), kemudian faktor fisik kulit dengan nilai $0.1242(12 \%)$, warna kulit 0.2357 (23\%).

4. Dari hasil analisis matrik AHP diperoleh model keputusan, dengan prioritas yaitu untuk seluruh bobot / prioritas kriteria dan alternatif yang menjadi prioritas pemilihan kualitas kulit ular di CV. Asia Exotica Medan adalah kulit peringkat 1 radiata dengan nilai 0.3190 (32\%), peringkat 2 kulit mangrove dengan nilai 0.2857 (28\%), peringkat 3 kulit phyton dengan nilai 0.2700 (27\%), peringkat 4 kulit sunbean dengan nilai $0.1262(12 \%)$.

5. Metode AHP ternyata dapat digunakan dalam proses penentuan kulit ular pada CV. Asia Exotica Medan, karena metode tersebut mampu menyelesaikan masalah multikriteria yang belum terstruktur menjadi lebih terstruktur dan lebih mudah dipahami dengan hasil yang akurat.

6. Model sistem pendukung keputusan untuk penentuan kualitas kulit ular pada CV. Asia Exotica Medan menggunakan metode AHP, mempunyai 3 kriteria yaitu ukuran kulit, fisik 
kulit, warna kulit sedangkan untuk alternatif terdiri dari: kulit phyton, kulit sunbean, kulit radiata dan kulit mangrove.

7. Dari hasil perbandingan, didapatkan hasil akurasi manual dan dengan Software Super Decisions terendah $80 \%$ dan akurasi tertinggi $95 \%$.

\section{SARAN}

Berdasarkan hasil analisa yang diperoleh, agar penerapan dan kelanjutan sistem pengambilan keputusan ini bisa lebih baik lagi, penulis menyarankan:

1. Pada penelitian ini penulis hanya menggunakan kuisioner sebanyak 1 orang, semakin banyak kuisioner yang digunakan dalam pengumpulan data maka hasil analisis akan jauh lebih baik lagi.

2. Perlunya ketelitian saat melakukan perhitunggan berpasangan baik kriteria maupun alternatif, kesalahan pada pemasukan data dapat menyebabkan hasil akhir tidak terpenuhi.

3. Bagi para peneliti yang ingin mengembangkan lebih luas dan lebih dalam lagi untuk menentukan media informasi sistem pengambilan keputusan ini dapat ditingkatkan dengan menambahkan kriteria dan alternatif-alternatif yang lebih banyak dan lebih bervariasi dengan melengkapi dan menambahkan cluster beserta node pada Super Decision untuk media penyampaian informasi pada masa yang akan datang.

4. Agar penelitian ini lebih baik lagi diharapkan bagi para peneliti bisa membuat aplikasi Sistem Pendukung Keputusan dengan metode AHP yang sudah dijelaskan oleh peneliti sebelumnya agar SPK ini lebih bermanfaat dan dapat digunakan dan dimengerti fungsi dan tujuan sistem ini oleh orang banyak.

\section{DAFTAR PUSTAKA}

[1] Magdalena, H., 2012, Sistem Pendukung Keputusan Untuk Menentukan Mahasiswa Lulusan Terbaik di Perguruan Tinggi, Seminar Nasional Teknologi Informasi dan Komunikasi 2012 (SENTIKA 2012), Yogyakarta, 10 Maret 2012.

[2] Turban, E, Aronson, J. E., Liang, T. P., 2005, Decision Support System and Intelligent Systems Edisi 7 Jilid 1, Andi Offset, Yogyakarta.

[3] Anshori, Y., 2012, Pendekatan Triangular Fuzzy Number Dalam Metode Analytical Hierarchy Process, Jurnal Ilmiah Foristek, vol 2, no 1, hal 126-135.

[4] Hamdani, R., Tjong, D. H., Herwina, H., 2013, Potensi Herpetfauna Dalam Pengobatan Tradisional di Sumatera Barat, Jurnal Biologi Universitas Andalas, vol 2, no 2, hal 110117. 